\title{
Effect of eccentric and concentric squat exercise on quadriceps thickness and lower extremity performance in healthy young males
}

\author{
Nihal Büker ${ }^{1 凶}$, Raziye Şavkın¹, Akın Süzer², and Nuray Akkaya ${ }^{3}$ \\ ${ }^{1}$ School of Physical Therapy and Rehabilitation, Pamukkale University, Denizli, Turkey; ${ }^{2}$ Therapy and Rehabilitation Department, \\ Burdur Vocational School of Health Services, Burdur Mehmet Akif Ersoy University, Burdur, Turkey; and ${ }^{3}$ Department of Physical \\ Medicine and Rehabilitation, Medical School, Pamukkale University, Denizli, Turkey
}

\begin{abstract}
Background: In clinical practice, resistance training, which includes concentric and eccentric dynamic muscle movements, is widely used by physiotherapists to strengthen the quadriceps muscle. However, although eccentric training is assumed to induce greater hypertrophy compared to concentric contractions, there are also studies reporting that similar increases in muscle thickness can be seen in both eccentric and concentric training. Objective: This study aims to assess the effect of the eccentric and concentric squat exercise on quadriceps thickness, and lower extremity performance during jumping and walking in healthy young sedentary males. Methods: Participants were randomly divided into three groups: concentric exercise group (CE; $n=19$ ), eccentric exercise group (EE; $n=13$ ) and control group (CG; $n=16$ ). Both exercises were performed seven days a week, for eight weeks with a gradual strength increase. The CG was not given any exercise. Ultrasound assessment of quadriceps muscle thickness, performance in Six-Minute Walk Test and vertical jump was measured. Results: Thickness of dominant side of rectus femoris $(p=.008)$ and vastus lateralis $(p=.021)$ differed significantly among the three groups; post hoc analysis revealed the thickness of rectus femoris in CG was significantly lower than in the CE $(p=.046)$ and EE $(p=.006)$ and the thickness of vastus lateralis in the EE was significantly higher than in the CG $(p=.018)$. Six-Minute Walk Test score in the EE was significantly higher than in the CG $(p=.025)$ and the vertical jump score in the CG significantly lower than in the EE $(p=.002)$ and CE $(p<.001)$. Conclusions: Eccentric and concentric training both benefits muscle hypertrophy and lower extremity functional performance. However, eccentric training also appears to offer a small advantage over concentric training.
\end{abstract}

Keywords: muscle contraction, isotonic contraction, muscle hypertrophy, functional performances, ultrasonography

\section{Introduction}

The quadriceps femoris is the most voluminous muscle group of the human body (Bordoni \& Varacallo, 2021). This muscle group contracts concentrically or eccentrically in daily physical activities, such as walking, ascending, and descending stairs, standing up from a chair or sitting on a chair (Gür et al., 2002). Furthermore, activation of proprioceptive afferents of the muscle improves contralateral quadriceps femoris coordination, thereby contributing to maintaining proper posture and increasing postural balance (Bordoni \& Varacallo, 2021). Despite all these important functions, atrophy and weakness of the quadriceps muscle group can be observed due to various knee problems (Giles et al., 2013; Petterson et al., 2008).

In clinical practice, open (seated knee extension, straight leg raise etc.) and closed kinetic chain exercises (leg press, squatting, sit-to-stand etc.) are widely used by physiotherapists to strengthen the quadriceps muscle (Kooiker et al., 2014). However, conventional multi-joint, closed kinetic chain exercises have several advantages because both proximal and distal body segments receive resistance training at the same time, allowing weight-bearing for the lower extremity, and produce superior eccentric contraction and co-contraction of the muscles, also reduce shear forces while adding compressive forces to the joints. In this context, squat exercise, which is frequently used in the clinical setting, simulate functional activities, create minimal stress on the patellofemoral joint in the functional range of motion, and allow the use of muscles that contribute to joint stability (Dionisio et al., 2013; Escamilla, 2001).

Resistance training, which includes concentric and eccentric dynamic muscle actions, is widely used as a method of gaining muscle strength to increase athletic performance, prevent injuries and maintain a healthy lifestyle (Roig et al., 2009). It is assumed that eccentric training leads to greater hypertrophy compared to concentric contractions, as it provides greater morphological and neuromuscular adaptation, a faster increase in protein synthesis, and a greater mechanical load that occurs with active elongation (Farthing \& Chilibeck, 2003; Roig et al., 2009). On the contrary, studies are reporting that similar increases can

$\square$ Corresponding author: Nihal Büker, e-mail bukernihal@gmail.com, ORCID ${ }^{\circledR}$ record https://orcid.org/0000-0001-7259-7983

Article history: Received January 4 2021, Accepted June 8 2021, Published July 282021

Copyright: @ 2021 The Author(s). Published by Palacký University Olomouc. This is an open access article distributed under the terms of the Creative Commons Attribution License (https://creativecommons.org/licenses/by/4.0/), which permits unrestricted use, distribution, and reproduction in any medium, provided the original author and source are credited. This license does not cover any third-party material that may appear with permission in the article. 
be observed regarding muscle thickness in both eccentric and concentric training (Blazevich et al., 2007; Cadore et al., 2014; Franchi et al., 2015; Santos et al., 2018; Timmins et al., 2016). It is thought that these contradictory results may arise from the different evaluation methods used (Roig et al., 2009).

The main purpose of this study was to determine the effect of the eccentric and concentric squat exercises on quadriceps thickness, and lower extremity performance during jumping and walking in healthy young sedentary males.

\section{Methods}

\section{Participants}

This study was conducted at the School of Physical Therapy and Rehabilitation at Pamukkale University and was approved by the Non-invasive Clinical Research Ethics Committee and an informed consent form was signed by all participants.

Inclusion criteria were as follows: male gender, age between 20 to 25 years, not participating in any resistance training, exercise, and physical activity program in the previous 3 months and who were inactive categories according to International Physical Activity QuestionnaireShort Form. Exclusion criteria were as follows: history of metabolic, cardiovascular, hormonal, respiratory diseases, or musculoskeletal disorders (e.g., patellofemoral pain syndrome, knee surgeries, and recent muscle strains).

A total of 60 male participants were randomly divided into three groups: concentric exercise group (CE; $n=20$ ), eccentric exercise group (EE; $n=20$ ) and control group (CG; $n=20)$. In CE, one participant was excluded because of incomplete data. In the EE, seven participants were excluded because of not attending exercise sessions regularly $(n=3)$, did not participate in the last evaluation $(n=2)$, inability to measure the thickness of the quadriceps muscle $(n=2)$. In the CG, four participants were excluded because of the inability to measure the thickness of the quadriceps muscle $(n=2)$ and incomplete data $(n=2)$. The final study sample consisted of 48 participants, with 19 in CE, 13 in EE and 16 in CG.

\section{Intervention}

The participants in the concentric and eccentric groups arrived at the clinic in the morning (08:30 to $11: 30)$ and cycled on an ergometer for five minutes at an intensity that resulted in a heart rate of around 130 beats per minute. Later, the participants completed eccentric and concentric squats described by Jonsson and Alfredson (2005). The exercise program consisted of three sets of ten repetitions each, performed seven days a week, for eight weeks under supervision. The rest interval between sets was two minutes. The intensity of exercise was standardized using the Rating of Perceived Exertion scale 6-20. After each exercise set, participants were asked to rate their exertion on the scale during the exercise, taking into account feelings of physical stress and fatigue ("How hard you feel your body has worked?”). The exercises were aimed to be performed at a moderate intensity (12-14), "somewhat difficult" (Farthing \& Chilibeck, 2003; Franchi et al., 2015; Petschnig et al., 1998). According to the participants' rating, the progress of the exercise intensity was achieved by adding weight to the backpacks with weights of $0.5 \mathrm{~kg}$ each. Throughout all sets, oral encouragement was given to elicit maximal effort.

The participants were instructed to complete the exercises with the trunk upright position. The purpose was to minimize gluteal muscle activity and relax the calf muscles to increase the demands of the knee extensor muscles while standing on a $25^{\circ}$ decline board.

\section{Concentric exercise group}

The starting position was standing (trunk upright) on the $25^{\circ}$ decline board with the entire body weight on the dominant leg with the knee in $70^{\circ}$ flexion. From that position, the knee was slowly straightened to full extension (Figure 1). To return to the starting position, the nondominant leg was used. Eccentric quadriceps activity was avoided as much as possible.

\section{Eccentric exercise group}

The starting position was standing (trunk upright) on the $25^{\circ}$ decline board with the entire body weight on the dominant leg. From that position, the knee was slowly flexed to $70^{\circ}$ (Figure 2). To return to the starting position, the nondominant leg was used. Concentric quadriceps activity was avoided as much as possible.

\section{Control group}

The control group was not given any exercise.

Participants in all groups were asked not to participate in sports, recreation, and exercise activities for eight weeks period.

\section{Data collection}

All participants were evaluated by the same researcher, who was blinded to the groups at baseline and the end of the 8th week.

\section{Ultrasound assessment}

The ultrasonographic examinations were performed using a 7-13 MHz linear probe (Logiq P5, GE Medical Systems, Wauwatosa, WI, USA) by a physician who was blinded to the groups. Ultrasonographic muscle thickness measurements were taken bilaterally (dominant/non-dominant). All thickness measurements were repeated three times for each site, and the average values of the three successive measurements for each region were recorded. Measurements were performed according to recommendations of the European Society of Musculoskeletal Radiology (Beggs et al., 2016).

\section{Rectus femoris and vastus lateralis thickness}

Participants were lying in a supine position with their knee fully extended and toes pointing to the ceiling. The transducer was placed on the thigh on a longitudinal plane. Images were taken at the level of the mid-thigh (mid-point 
Figure 1 Starting $(A)$ and end (B) position for concentric quadriceps exercise
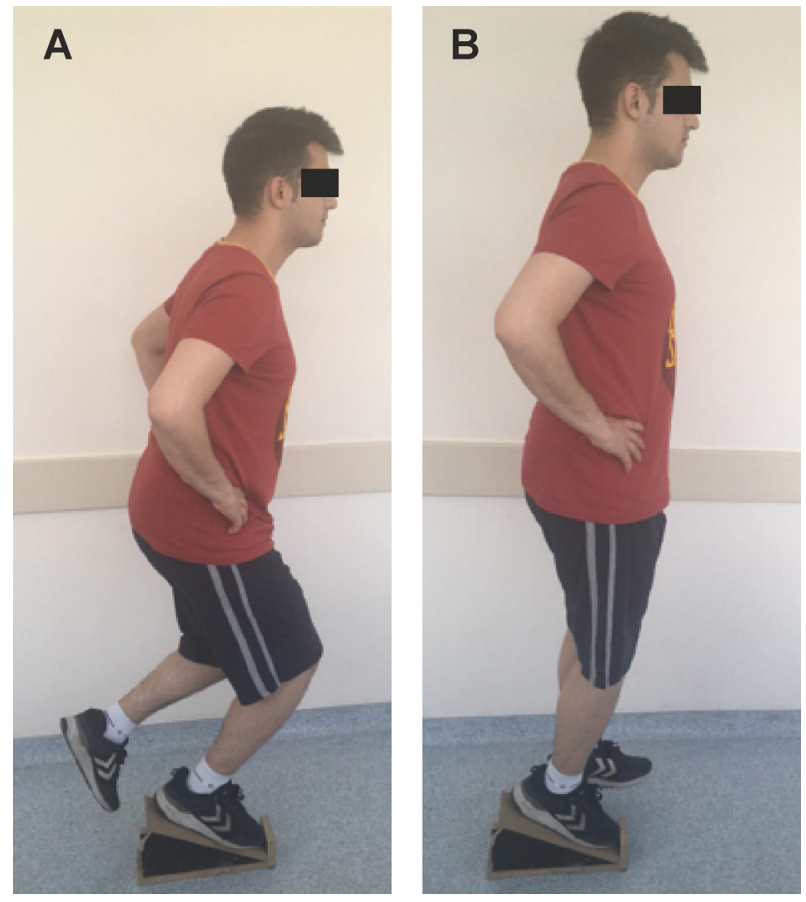

of the distance from the lateral condyle of the femur to the central palpable point of the greater trochanter) at baseline and after the exercise program with the application of the same standardized procedure.

\section{Quadriceps and patellar tendon thickness}

Participants were lying in a supine position with their knee flexed at $-30^{\circ}$. Measurements were performed with a longitudinal probe position at midpoints of the quadriceps (between the proximal musculotendinous part and the most proximal part of the patellar insertion), and patellar tendon (between the distal pole of the patella and the most proximal part of the tibial tubercle insertion of the tendon).

\section{Six-Minute Walk Test}

Participants were sat at rest in a chair for at least 10 minutes before the test. The walking course was $30 \mathrm{~m}$ in length. The test was carried out following the American Thoracic Society Guideline (ATS Committee on Proficiency Standards for Clinical Pulmonary Function Laboratories, 2002). Walking distance was recorded in meters.

\section{Vertical jump}

The difference in distance between participant's standing reach (the point of the fingertips when the participant reaches upward with the hand closest to the wall with their feet flat on the ground) and the height to which he can jump (the participant jumps vertically as high as possible, keeping away from the wall, using both their arms and legs to help lift the body upward) and touch were determined. The test was performed three times and the best of three attempts is recorded in centimeters (Petschnig et al., 1998).
Figure 2 Starting (A) and end (B) position for eccentric quadriceps exercise
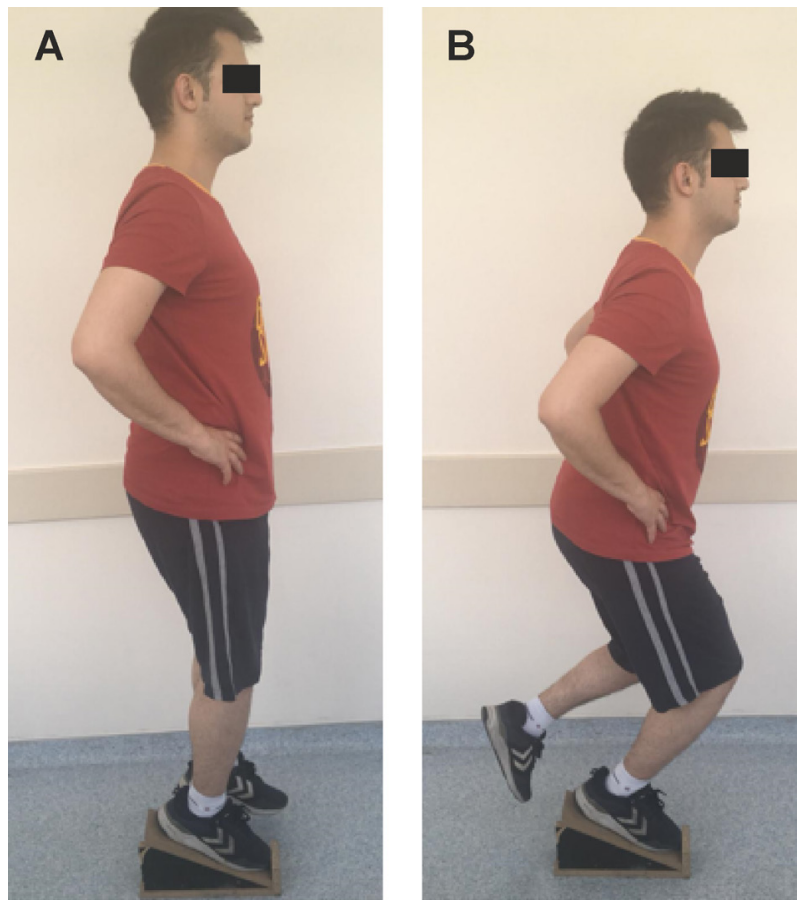

\section{Statistical analysis}

Obtained data were analyzed using SPSS Statistics (Version 21; IBM, Armonk, NY, USA). Continuous variables were presented as mean \pm standard deviation, maximum and minimum and categorical variable values were presented as absolute frequency and percentages. The conformity of continuous variables with normal distribution was evaluated using the Shapiro-Wilk test. For pairwise comparisons, if parametric test conditions were satisfied paired samples $t$-test; and if parametric test conditions were not satisfied Wilcoxon signed-rank test was used (dominant and nondominant extremity rectus femoris thickness of EE group, dominant extremity vastus lateralis thickness of CE group, Six-Minute Walk Test score of all groups and a vertical jump score of CE and CG groups were not distributed normally). The percentage of individual changes was calculated with the following formula: [(Post - Pre $) /$ Pre $]^{*} 100$. To compare percentage changes among groups, we used analysis of variance (ANOVA; post-hoc: Tukey test) when parametric test conditions were satisfied (dominant extremity rectus femoris thickness, non-dominant extremity patellar tendon thickness were distributed normally) and Kruskal-Wallis variance analysis (post-hoc: Mann-Whitney $U$ test with Bonferroni correction) when parametric test conditions were not satisfied. Effect size estimates were calculated as follows: Cohen's $d(t / \sqrt{ } N)$ for parametric test conditions, $r$ coefficient $(Z / \sqrt{ } N)$ for nonparametric test conditions and eta-squared $\left(\eta^{2}\right)$ for ANOVA. A $p$-value $\leq .05$ was considered statistically significant. 


\section{Results}

Forty-eight males with age $23.11 \pm 0.87$ years in $\mathrm{CE}$ and $23.23 \pm 1.16$ years in $\mathrm{EE}$ and $22.81 \pm 0.65$ years in CG group participated in the study. Seventeen $(89.5 \%)$ subjects in the CE group, 10 (76.9\%) in the EE group, and 16 (100\%) in the CG group presented right-leg dominance. Descriptive data of participants were shown in Table 1.

There was no difference between the groups at baseline, except dominant extremity quadriceps tendon thickness $(p=.029)$ and Six-Minute Walk Test $(p=.035)$. Post hoc analysis revealed the quadriceps tendon thickness in CG significantly higher than in the CE $(p=.052)$ and the SixMinute Walk Test score of the CE significantly lower than in the $\mathrm{EE}(p=.044)$.

Dominant side rectus femoris (CE: $p=.002, d=.919$; $\mathrm{EE}: p=.006, r=0.618$ ), vastus lateralis (CE: $p=.023$, $r=0.552$; EE: $p<.001, d=1.072)$ and quadriceps tendon thickness (CE: $p=.044, d=.548$; EE: $p=.046$, $d=.477$ ) was increased significantly after eight weeks in the $\mathrm{CE}$ and $\mathrm{EE}$ groups (Figure 3). Dominant side rectus femoris $\left(p=.008, \eta^{2}=.191\right)$ and vastus lateralis $(p=.021$, $r=.157)$ differed significantly among the three groups; post hoc analysis revealed the rectus femoris in CG significantly lower than in the CE $(p=.046, d=.649)$ and EE $(p=.006, d=.539)$ and the vastus lateralis in the EE was significantly higher than in the CG $(p=.018, r=.710)$. At the same time, nondominant side vastus lateralis thickness were significantly lower in CG than EE $(p=.032$, $r=.450$; Table 2).

There was a statistically significant increase in the SixMinute Walk Test (CE: $p=.010, r=.594$; EE: $p=.012$,

Table 1 Descriptive data of participants at baseline

\begin{tabular}{lccc}
\hline & $\begin{array}{c}\text { Concentric } \\
\text { exercise }(n=19)\end{array}$ & $\begin{array}{c}\text { Eccentric } \\
\text { exercise }(n=13)\end{array}$ & $\begin{array}{c}\text { Controls } \\
(n=16)\end{array}$ \\
\hline Age (years) & & & \\
$M \pm S D$ & $23.11 \pm 0.87$ & $23.23 \pm 1.16$ & $22.81 \pm 0.65$ \\
Range & $22-25$ & $21-25$ & $22-24$ \\
Body mass index $\left(\mathrm{kg} / \mathrm{m}^{2}\right)$ & & \\
$M \pm S D$ & $22.56 \pm 3.86$ & $22.09 \pm 2.13$ & $23.82 \pm 2.29$ \\
Range & $16.76-30.12$ & $17.75-24.77$ & $21.26-30.61$ \\
Dominant lower extremity $(n(\%))$ & & \\
Right & $17(89.5)$ & $10(76.9)$ & $16(100.0)$ \\
Left & $2(10.5)$ & $3(23.1)$ & $0(0.0)$ \\
\hline
\end{tabular}

Table 2 Ultrasonographic evaluation of muscle thickness

\begin{tabular}{|c|c|c|c|c|c|c|}
\hline Variable & Pre & Post & Intra-group $p$ & Effect size & $\Delta$ change (\%) & Inter-group $p$ \\
\hline \multicolumn{7}{|c|}{ Dominant extremity } \\
\hline Rectus femoris (cm) & & & & & & $.008^{1-3,2-3}$ \\
\hline $\mathrm{CE}$ & $1.569 \pm 0.308$ & $1.723 \pm 0.323$ & .002 & 0.919 & $12.4 \pm 12.7$ & \\
\hline $\mathrm{EE}$ & $1.610 \pm 0.461$ & $1.800 \pm 0.313$ & .006 & 0.618 & $16.0 \pm 19.0$ & \\
\hline CG & $1.840 \pm 0.288$ & $1.817 \pm 0.274$ & .404 & 0.251 & $-1.1 \pm 4.7$ & \\
\hline Patellar tendon $(\mathrm{cm})$ & & & & & & .511 \\
\hline CE & $0.325 \pm 0.052$ & $0.340 \pm 0.051$ & .266 & 0.279 & $6.3 \pm 18.45$ & \\
\hline $\mathrm{EE}$ & $0.350 \pm 0.051$ & $0.359 \pm 0.042$ & .452 & 0.172 & $3.9 \pm 15.6$ & \\
\hline CG & $0.343 \pm 0.030$ & $0.344 \pm 0.026$ & .901 & 0.037 & $0.7 \pm 8.7$ & \\
\hline Vastus lateralis $(\mathrm{cm})$ & & & & & & $.021^{2-3}$ \\
\hline CE & $1.938 \pm 0.478$ & $2.055 \pm 0.389$ & .023 & 0.552 & $8.9 \pm 19.3$ & \\
\hline $\mathrm{EE}$ & $1.948 \pm 0.441$ & $2.162 \pm 0.400$ & $<.001$ & 1.072 & $12.2 \pm 10.5$ & \\
\hline CG & $2.258 \pm 0.289$ & $2.212 \pm 0.287$ & .139 & 0.460 & $-1.9 \pm 4.5$ & \\
\hline Quadriceps tendon (cm) & & & & & & .621 \\
\hline CE & $0.417 \pm 0.058$ & $0.455 \pm 0.060$ & .044 & 0.548 & $12.2 \pm 22.7$ & \\
\hline $\mathrm{EE}$ & $0.439 \pm 0.055$ & $0.472 \pm 0.045$ & .046 & 0.477 & $9.4 \pm 18.5$ & \\
\hline CG & $0.450 \pm 0.040$ & $0.468 \pm 0.044$ & .295 & 0.333 & $4.9 \pm 13.1$ & \\
\hline \multicolumn{7}{|c|}{ Non-dominant extremity } \\
\hline Rectus femoris (cm) & & & & & & .191 \\
\hline CE & $1.597 \pm 0.359$ & $1.578 \pm 0.322$ & .774 & 0.071 & $0.4 \pm 17.2$ & \\
\hline $\mathrm{EE}$ & $1.480 \pm 0.348$ & $1.597 \pm 0.342$ & .381 & 0.388 & $10.2 \pm 20.8$ & \\
\hline CG & $1.771 \pm 0.354$ & $1.752 \pm 0.309$ & .794 & 0.077 & $0.2 \pm 14.2$ & \\
\hline Patellar tendon $(\mathrm{cm})$ & & & & & & .523 \\
\hline CE & $0.322 \pm 0.047$ & $0.338 \pm 0.044$ & .127 & 0.439 & $5.9 \pm 12.3$ & \\
\hline $\mathrm{EE}$ & $0.349 \pm 0.065$ & $0.344 \pm 0.028$ & .715 & 0.085 & $0.9 \pm 15.3$ & \\
\hline CG & $0.338 \pm 0.027$ & $0.347 \pm 0.030$ & .080 & 0.558 & $2.5 \pm 4.6$ & \\
\hline Vastus lateralis (cm) & & & & & & $.032^{2-3}$ \\
\hline $\mathrm{CE}$ & $1.858 \pm 0.480$ & $1.923 \pm 0.391$ & .214 & 0.324 & $5.9 \pm 15.0$ & \\
\hline $\mathrm{EE}$ & $1.896 \pm 0.415$ & $2.021 \pm 0.299$ & .052 & 0.464 & $9.2 \pm 17.1$ & \\
\hline CG & $2.230 \pm 0.316$ & $2.156 \pm 0.287$ & .087 & 0.543 & $-3.0 \pm 6.1$ & \\
\hline Quadriceps tendon (cm) & & & & & & .887 \\
\hline CE & $0.422 \pm 0.044$ & $0.436 \pm 0.049$ & .359 & 0.254 & $3.980 \pm 13.452$ & \\
\hline $\mathrm{EE}$ & $0.424 \pm 0.066$ & $0.440 \pm 0.035$ & .263 & 0.265 & $5.976 \pm 17.286$ & \\
\hline CG & $0.418 \pm 0.042$ & $0.439 \pm 0.039$ & .248 & 0.352 & $6.069 \pm 14.377$ & \\
\hline
\end{tabular}

Note. $\mathrm{CE}=$ concentric exercise; $\mathrm{EE}=$ eccentric exercise; $\mathrm{CG}=$ controls. Statistically significant differences in post-hoc tests between groups: ${ }^{1-3} \mathrm{CE}$ vs. $\mathrm{CG} ;{ }^{2-3} \mathrm{EE}$ vs. $\mathrm{CG}$. 
$r=.699)$ and vertical jump (CE group: $p=.001, r=.792$; EE group: $p=.002, d=1.056)$ after eight weeks in the CE and EE groups (Figure 4). Six-Minute Walk Test differed significantly among the three groups ( $p=.047, r=.180$ ); post hoc analysis revealed the Six-Minute Walk Test score in the EE was significantly higher than in the CG $(p=.025$, $r=.470)$. Vertical jump differed significantly among the groups $(p<.001, r=.289)$; post hoc analysis revealed the vertical jump score in the CG significantly lower than in the $\mathrm{EE}(p=.002, r=.650)$ and $\mathrm{CE}(p<.001, r=.640$; Table 3).

\section{Discussion}

In this study, we aimed to compare the effect of eccentric and concentric squat exercise in terms of quadriceps thickness, and lower extremity performance during jumping and walking in healthy sedentary young males. Both eccentric and concentric squats increased the thickness of

Figure 3 Comparison of ultrasonographic evaluation of rectus femoris, vastus lateralis and quadriceps tendon thickness on the dominant side
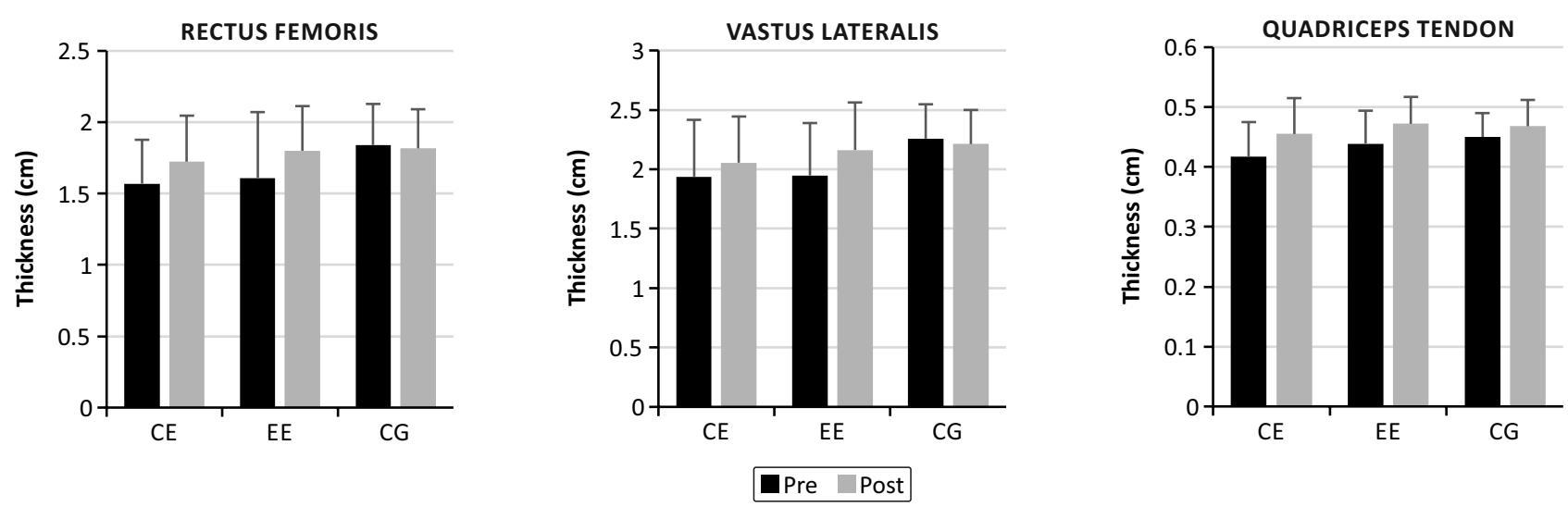

Note. $\mathrm{CE}=$ concentric exercise; $\mathrm{EE}=$ eccentric exercise; $\mathrm{CG}=$ controls

Figure 4 Comparison of lower extremity performance measurements
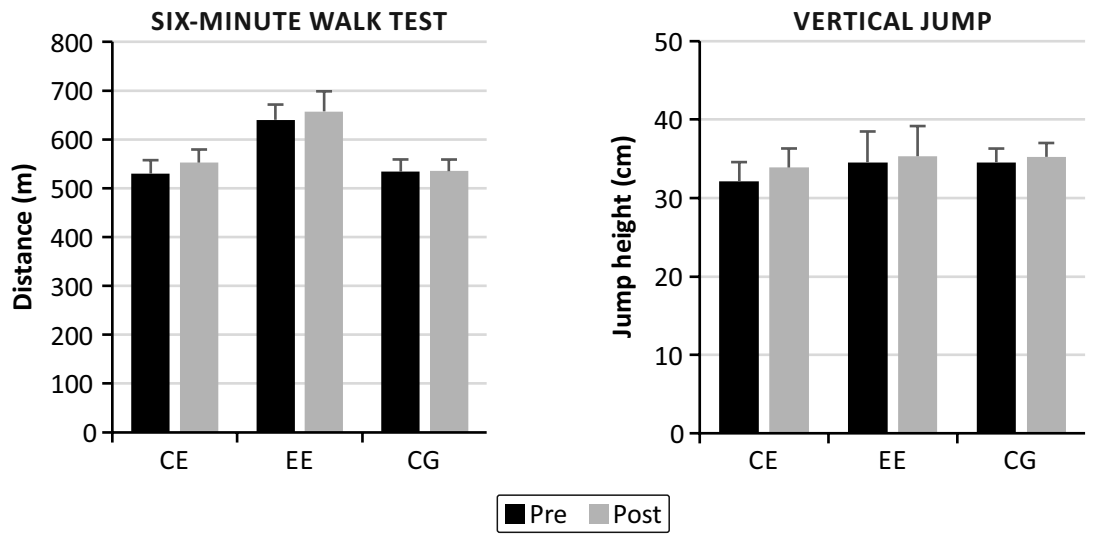

Note. $\mathrm{CE}=$ concentric exercise; $\mathrm{EE}=$ eccentric exercise; $\mathrm{CG}=$ controls .

Table 3 Lower extremity performance measurements

\begin{tabular}{|c|c|c|c|c|c|c|}
\hline Variable & Pre & Post & Intra-group $p$ & Effect size & $\Delta$ change (\%) & Inter-group $p$ \\
\hline Six-minute walk test (m) & & & & & & $.047^{2-3}$ \\
\hline $\mathrm{CE}$ & $530.00 \pm 27.57$ & $552.53 \pm 26.86$ & .010 & 0.594 & $5.31 \pm 5.77$ & \\
\hline $\mathrm{EE}$ & $640.23 \pm 31.18$ & $657.38 \pm 41.18$ & .012 & 0.699 & $3.81 \pm 3.10$ & \\
\hline CG & $533.75 \pm 25.23$ & $535.00 \pm 23.84$ & .359 & 0.229 & $0.71 \pm 3.10$ & \\
\hline Vertical jump (cm) & & & & & & $<.001^{1-3,2-3}$ \\
\hline $\mathrm{CE}$ & $32.16 \pm 2.42$ & $33.89 \pm 2.43$ & .001 & 0.792 & $6.06 \pm 5.72$ & \\
\hline $\mathrm{EE}$ & $34.55 \pm 3.94$ & $35.33 \pm 3.85$ & .002 & 1.056 & $4.54 \pm 3.82$ & \\
\hline CG & $34.56 \pm 1.75$ & $35.25 \pm 1.77$ & .234 & 0.297 & $0.07 \pm 2.29$ & \\
\hline
\end{tabular}

Note. $\mathrm{CE}=$ concentric exercise; $\mathrm{EE}=$ eccentric exercise; $\mathrm{CG}=$ controls. Statistically significant differences in post-hoc tests between groups: ${ }^{1-3} \mathrm{CE}$ vs. $\mathrm{CG} ;{ }^{2-3} \mathrm{EE}$ vs. $\mathrm{CG}$. 
the dominant side rectus femoris, vastus lateralis and quadriceps tendon, but the eccentric squat had a greater effect compared to percentages of change between groups. Similar findings were also obtained in the Six-minute Walk Test and vertical jump score outcomes.

Roig et al. (2009) concluded that eccentric training is superior to concentric training in terms of promoting strength, but this is highly specific to the contraction type and velocity in healthy adults. However, most of the studies included in this meta-analysis involved isokinetic resistance training. In isotonic resistance exercise, this situation has been examined using varying movement tempos (Pryor et al., 2011; Schoenfeld et al., 2015; Wilk et al., 2018). It is claimed that slow isotonic resistance training is more effective at increasing strength than fast isotonic resistance training (Burd et al., 2012; Farthing et al., 2003; Pereira et al., 2016; Roig et al., 2009). In a recent meta-analysis, eccentric muscle training resulted in a greater effect compared to concentric training, but the results did not increase to statistical significance (Schoenfeld et al., 2017). Similarly, we observed significant thickening in the rectus femoris and vastus lateralis muscles in both the EE and CE groups. However, in terms of effect size, rectus femoris thickness was greater in the CE group and vastus lateralis thickness in the EE group. Studies show that particular eccentric and concentric cadence values can cause different adaptive responses in the muscle. Training at different movement tempo can provide different gains in terms of strength development and muscle hypertrophy. For this reason, our failure to control the pace of movement may affect the results. However, we did not control the movement tempo in our study, which may affect the results.

Functional performance tests are considered an alternative method for evaluating muscle strength due to their simplicity and being more time-efficient and cost-effective than isometric or isokinetic instrumentation (Kollock et al., 2015). Traditional resistance training is known to increase aerobic capacity and muscle strength (Moro et al., 2020; Sentija et al., 2009). Resistance training can increase aerobic capacity in young individuals by providing improvements in capillary-to-fiber ratio and mitochondrial enzyme activity (Ozaki et al., 2013). In our study, an increase in aerobic capacity was achieved in both exercise groups. The effect size was moderate. However, to our knowledge, there is no study comparing the effects of eccentric and concentric training on aerobic capacity. However, numerous studies have investigated the effects of different knee extensor training on knee strength, but the results are highly variable. However, although many studies have reported a greater increase in muscle strength after eccentric training (Farthing \& Chilibeck, 2003; Franchi et al., 2014; Reeves et al., 2009), some studies have reported that concentric training has the same effect (Blazevich et al., 2007; Farthing \& Chilibeck, 2003; Tomberlin et al., 1991). Similarly, according to the results of our study, both concentric and eccentric exercises were beneficial in terms of increasing muscle strength and had a large effect size.

Lack of multiple sampling sites along the length of the quadriceps muscle (eccentric and concentric actions can produce regional-specific effects on muscle growth) and uncontrolled movement tempo are limitations of our study. Further studies can be conducted involving different resistance training models in which movement tempo is controlled and multiple sampling sites are evaluated. In addition, the cross-sectional area of the muscle can be measured by imaging methods such as magnetic resonance or computed tomography. Muscle strength can also be determined with isokinetic devices or a dynamometer.

\section{Conclusions}

Eccentric and concentric training both benefits muscle hypertrophy and lower extremity performance. However, it also appears that eccentric training probably offers a small advantage over concentric training. According to our results, muscle thickness and functional performance can be increased in healthy young adults with simple, easy, and well-designed exercises that do not require special equipment and space.

\section{Acknowledgments}

We would like to thank Assist. Prof. Hande Senol for her statistical support.

\section{Conflict of interest}

The authors report no conflict of interest.

\section{References}

ATS Committee on Proficiency Standards for Clinical Pulmonary Function Laboratories (2002). ATS statement: Guidelines for the six-minute walk test. American Journal of Respiratory and Critical Care Medicine, 166(1), 111-117. https://doi. org/10.1164/airccm.166.1.at1102

Beggs, I., Bianchi, S., Bueno, A., Cohen, M., Court-Payen, J., Grainger, A., Klauser, A., Kainberger, F., Martinoli, C., McNally, E., O'Connor, P. J., Peetrons, P., Reijnierse, M., Remplik, P., \& Silvestri, E. (2016). Musculoskeletal ultrasound technical guidelines: V. knee. https://essr.org/content-essr/uploads/2016/10/knee.pdf

Blazevich, A. J., Cannavan, D., Coleman, D. R., \& Horne, S. (2007). Influence of concentric and eccentric resistance training on architectural adaptation in human quadriceps muscles. Journal of Applied Physiology, 103(5), 1565-1575. https://doi.org/10.1152/japplphysiol.00578.2007

Bordoni, B., \& Varacallo, M. (2021). Anatomy, bony pelvis and lower limb, thigh quadriceps muscle. https://www.ncbi.nlm.nih.gov/books/NBK513334/

Burd, N. A., Andrews, R. J., West, D. W., Little, J. P., Cochran, A. J., Hector, A. J., Cashaback, J. G., Gibala, M. J., Potvin, J. R., Baker, S. K., \& Phillips, S. M. (2012). Muscle time under tension during resistance exercise stimulates differential muscle protein sub-fractional synthetic responses in men. Journal of Physiology, 590(2), 351-362. https://doi.org/10.1113/iphysiol.2011.221200

Cadore, E. L., González-Izal, M., Pallarés, J. G., Rodriguez-Falces, J., Häkkinen, K., Kraemer, W. J., Pinto, R. S., \& Izquierdo, M. (2014). Muscle conduction velocity, strength, neural activity, and morphological changes after eccentric and concentric training. Scandinavian Journal of Medicine \& Science in Sports, 24(5), e343-e352. https://doi.org/10.1111/sms.12186

Dionisio, V. C., Azevedo, B. M. S., \& Siqueira, D. A. (2013). Horizontal and declined squats in healthy individuals: A study of kinematic and muscle patterns. International Scholarly Research Notices, 2013, Article 169808. https:// doi.org/10.1155/2013/169808

Escamilla, R. F. (2001). Knee biomechanics of the dynamic squat exercise. Medicine \& Science in Sports \& Exercise, 33(1), 127-141. https://doi. org/10.1097/00005768-200101000-00020

Farthing, J. P., \& Chilibeck, P. D. (2003). The effects of eccentric and concentric training at different velocities on muscle hypertrophy. European Journal of Applied Physiology, 89(6), 578-586. https://doi.org/10.1007/s00421-003-0842-2

Franchi, M. V., Atherton, P. J., Reeves, N. D., Flück, M., Williams, J., Mitchell, W. K., Selby, A., Beltran Valls, R. M., \& Narici, M. V. (2014). Architectural, functional and molecular responses to concentric and eccentric loading in human skeletal muscle. Acta Physiologica, 210(3), 642-654. https://doi.org/10.1111/apha.12225 
Franchi, M. V., Wilkinson, D. J., Quinlan, J. I., Mitchell, W. K., Lund, J. N., Williams, J. P., Reeves, N. D., Smith, K., Atherton, P. J., \& Narici, M. V. (2015). Early structural remodeling and deuterium oxide-derived protein metabolic responses to eccentric and concentric loading in human skeletal muscle. Physiological Reports, 3(11), Article e12593. https://doi.org/10.14814/phy2.12593

Giles, L. S., Webster, K. E., McClelland, J. A., \& Cook, J. (2013). Does quadriceps atrophy exist in individuals with patellofemoral pain? A systematic literature review with meta-analysis. Journal of Orthopaedic and Sports Physical Therapy, 43(11), 766-776. https://doi.org/10.2519/jospt.2013.4833

Gür, H., Cakin, N., Akova, B., Okay, E., \& Küçükoğlu, S. (2002). Concentric versus combined concentric-eccentric isokinetic training: Effects on functional capacity and symptoms in patients with osteoarthrosis of the knee. Archives of Physical Medicine and Rehabilitation, 83(3), 308-316. https://doi.org/10.1053/ apmr.2002.30620

Jonsson, P., \& Alfredson, H. (2005). Superior results with eccentric compared to concentric quadriceps training in patients with jumper's knee: A prospective randomised study. British Journal of Sports Medicine, 39(11), 847-850. https:// doi.org/10.1136/bjsm.2005.018630

Kollock, R., Van Lunen, B. L., Ringleb, S. I., \& Oñate, J. A. (2015). Measures of functional performance and their association with hip and thigh strength. Journal of Athletic Training, 50(1), 14-22. https://doi.org/10.4085/1062-6050-49.3.49

Kooiker, L., Van De Port, I. G., Weir, A., \& Moen, M. H. (2014). Effects of physical therapist-guided quadriceps-strengthening exercises for the treatment of patellofemoral pain syndrome: A systematic review. Journal of Orthopaedic and Sports Physical Therapy, 44(6), 391-402. https://doi.org/10.2519/iospt.2014.4127

Moro, T., Marcolin, G., Bianco, A., Bolzetta, F., Berton, L., Sergi, G., \& Paoli, A. (2020). Effects of 6 weeks of traditional resistance training or high intensity interval resistance training on body composition, aerobic power and strength in healthy young subjects: A randomized parallel trial. International Journal of Environmental Research and Public Health, 17(11), Article 4093. https://doi. org/10.3390/ijerph17114093

Ozaki, H., Loenneke, J. P., Thiebaud, R. S., \& Abe, T. (2013). Resistance training induced increase in $\mathrm{VO}_{2} \max$ in young and older subjects. European Review of Aging and Physical Activity, 10, 107-116. https://doi.org/10.1007/ s11556-013-0120-1

Pereira, P. E. A., Motoyama, Y. L., Esteves, G. J., Quinelato, W. C., Botter, L., Tanaka, K. H. \& Azevedo, P. (2016). Resistance training with slow speed of movement is better for hypertrophy and muscle strength gains than fast speed of movement. International Journal of Applied Exercise Physiology, 5(2), 37-43. https:// doi.org/10.30472/IJAEP.V512.51

Petschnig, R., Baron, R., \& Albrecht, M. (1998). The relationship between isokinetic quadriceps strength test and hop tests for distance and one-legged vertical jump test following anterior cruciate ligament reconstruction. Journal of
Orthopaedic and Sports Physical Therapy, 28(1), 23-31. https://doi.org/10.2519/ jospt.1998.28.1.23

Petterson, S. C., Barrance, P., Buchanan, T., Binder-Macleod, S., \& Snyder-Mackler, L. (2008). Mechanisms underlying quadriceps weakness in knee osteoarthritis. Medicine \& Science in Sports \& Exercise, 40(3), 422-427. https://doi. org/10.1249/MSS.0b013e31815ef285

Pryor, R. R., Sforzo, G. A., \& King, D. L. (2011). Optimizing power output by varying repetition tempo. Journal of Strength and Conditioning Research, 25(11), 3029-3034. https://doi.org/10.1519/JSC.0b013e31820f50cb

Reeves, N. D., Maganaris, C. N., Longo, S., \& Narici, M. V. (2009). Differential adaptations to eccentric versus conventional resistance training in older humans. Experimental Physiology, 94(7), 825-833. https://doi.org/10.1113/ exphysiol.2009.046599

Roig, M., O'Brien, K., Kirk, G., Murray, R., McKinnon, P., Shadgan, B., \& Reid, W. D. (2009). The effects of eccentric versus concentric resistance training on muscle strength and mass in healthy adults: A systematic review with meta-analysis. British Journal of Sports Medicine, 43(8), 556-568. https://doi.org/10.1136/ bjsm.2008.051417

Santos, R., Valamatos, M. J., Mil-Homens, P., \& Armada-da-Silva, P. (2018). Muscle thickness and echo-intensity changes of the quadriceps femoris muscle during a strength training program. Radiography, 24(4), e75-e84. https://doi. org/10.1016/i.radi.2018.03.010

Schoenfeld, B. J., Ogborn, D. I., \& Krieger, J. W. (2015). Effect of repetition duration during resistance training on muscle hypertrophy: A systematic review and meta-analysis. Sports Medicine, 45(4), 577-585. https://doi.org/10.1007/ $\underline{\text { s40279-015-0304-0 }}$

Schoenfeld, B. J., Ogborn, D. I., Vigotsky, A. D., Franchi, M. V., \& Krieger, J. W. (2017). Hypertrophic effects of concentric vs. eccentric muscle actions: A systematic review and meta-analysis. Journal of Strength and Conditioning Research, 31(9), 2599-2608. https://doi.org/10.1519/JSC.0000000000001983

Sentija, D., Marsić, T. \& Dizdar, D. (2009). The effects of strength training on some parameters of aerobic and anaerobic endurance. Collegium Antropologicum, 33(1), 111-116.

Timmins, R. G., Ruddy, J. D., Presland, J., Maniar, N., Shield, A. J., Williams, M. D. \& Opar, D. A. (2016). Architectural changes of the biceps femoris long head after concentric or eccentric training. Medicine \& Science in Sports \& Exercise, 48(3), 499-508. https://doi.org/10.1249/MSS.0000000000000795

Tomberlin, J. P., Basford, J. R., Schwen, E. E., Orte, P. A., Scott, S. C., Laughman, R. K., \& Ilstrup, D. M. (1991). Comparative study of isokinetic eccentric and concentric quadriceps training. Journal of Orthopaedic and Sports Physical Therapy, 14(1), 31-36. https://doi.org/10.2519/jospt.1991.14.1.31

Wilk, M., Golas, A., Stastny, P., Nawrocka, M., Krzysztofik, M., \& Zajac, A. (2018). Does tempo of resistance exercise impact training volume? Journal of Human Kinetics, 62, 241-250. https://doi.org/10.2478/hukin-2018-0034 